\title{
EI derecho al aborto en discusión: la interven- ción de grupos católicos en la comisión de salud de la Legislatura de la Ciudad de Buenos Aires
}

GABRIELA IRRAZÁBAL"

\section{Resumen}

El presente trabajo da cuenta de la participación de grupos católicos especializados en bioética y "bioderecho" en los debates parlamentarios sobre aborto no punible en la Comisión de Salud de la Ciudad de Buenos Aires a fines de 2008. Teniendo en cuenta las múltiples transferencias e influencias entre los campos político y religioso en Argentina, se intentará abordar la estrategia política que ciertos actores del catolicismo utilizan para consolidar la hegemonía simbólica de la Iglesia Católica en la regulación de la vida de los individuos, especialmente de las mujeres y la utilización de estas estrategias como apuestas de estos grupos para mantener su lugar hegemónico al interior de la Iglesia Católica.

Palabras-clave: Bioética. Bioderecho. Derecho al aborto. Mujeres y aborto.

* Licenciada en Sociología por la Universidad Nacional de La Plata, Argentina. Doctoranda en Ciencias Sociales de la Universidad de Buenos Aires. CEIL-PIETTE (Centro de Estudios e Investigaciones Laborales y Programa de Investigaciones Económicas sobre Tecnología, Trabajo y Empleo) / ANPCyT (Agencia Nacional de Promoción Científica y Tecnológica). 


\section{Introducción}

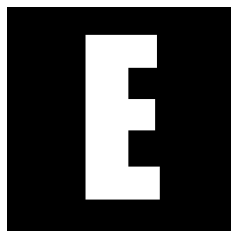

I aborto en Argentina es un tema ampliamente investigado desde las ciencias sociales. En general los trabajos giran en torno a seis cuestiones: 1) recopilaciones sobre la situación legal, las políticas públicas y su adecuación a los estándares internacionales y compromisos asumidos en el marco de Naciones Unidas; 2) la práctica de aborto clandestino y el "mercado de servicios" disponible para mujeres de sectores socio-económicos medios-altos y los riesgosos procedimientos en los que incurren las mujeres de sectores populares: 3) las prácticas de los médicos del sector público y su generalizada negativa a practicar abortos no punibles por temor a represalias penales; 4) la intervención de la justicia a pedido de los médicos del sector público en casos de aborto no punible (judicialización); 5) la incidencia de la interrupción de los embarazos como parte de procesos de regulación de la natalidad y 6) la opinión de los ciudadanos sobre la despenalización del aborto a partir de resultados de encuestas. ${ }^{1}$ Abundan también los estudios sobre la incidencia de los movimientos de

1 Sobre el abordaje es ciencias sociales ver GOGNA, Mónica. Estado del Arte. Investigación sobre sexualidad y derechos en Argentina (1990-2002), Buenos Aires, CEDES, 2005. Además ver ZAMBERLIN, N. El aborto en Argentina. Despenalización. Hoja Informativa no 3 junio de 2007. Disponible en www.despenalizacion.org.ar. PETRACCl, Mónica. Opinión pública sobre interrupción voluntaria del embarazo y despenalización del aborto en la Argentina y América Latina, Despenalización, Hoja informativa no 8 abril, 2007 disponible en www.despenalizacion.org.ar. RAMOS, Silvina. ROMERO, Mónica y BERGALLO, Paola. El acceso al aborto permitido por la ley: un tema pendiente de la política de derechos humanos en Argentina en Derechos Humanos en Argentina, Buenos Aires, Siglo XXI-CELS, 2009 pp. 451-491. GUTIÉRREZ, María Alicia. Silencios y susurros: la cuestión de la anticoncepción y el aborto en CÁCERES, Carlos F; FRASCA, Timothy; PECHENY, Mario; TERTO JÚNIOR, Veriano. Ciudadanía sexual en América Latina: abriendo el debate. Lima, Universidad Peruana Cayetano Heredia. 2004 pp.129-140. HEILBORN, María.; PETRACCI, Mónica y VIVEROS, Mara. Heterosexualidades, contracepción y aborto. Rio de Janeiro, CLAM, 2008, p.1-24. CORREA, Sonia. Aborto na cena política global: fios de história, desafios do momento en Ipas. Revista de Salud Sexual y Reproductiva, n. 18, 2004, p. 1-15. 
mujeres y feministas en la visibilización de esta temática y los logros políticos en cuanto a ampliación de derechos en materia de salud sexual y reproductiva. Diversos autores indican que las estrategias y acciones que fueron implementando los distintos grupos de mujeres a partir del trabajo en redes latinoamericanas, movimientos de base y participación en conferencias de organismos internacionales lograron ubicar en la sociedad política el tema del aborto. ${ }^{2}$ Por otra parte, se destacan las dificultades que tiene el sistema político argentino para discutir y "procesar el aborto" que llevan a evitar tomar decisiones de políticas y la existencia de "dobles discursos": los actores políticos se manifiestan "en contra" de ampliar la legislación del aborto pero toleran que se practique en condiciones de ilegalidad para las mujeres, a las que condenan socialmente (PECHENY, 2005, p. 7).

Al analizar la literatura sobre aborto se encuentra que en reiteradas oportunidades los/as autores destacan a la Iglesia Católica como uno de los principales "actores que obstaculizan" para la ampliación del acceso al aborto legal y seguro. En general se toman las estrategias de las jerarquías católicas como unívocas y homogéneas y existen pocos trabajos que describan minuciosamente las estrategias que adoptan algunos grupos de laicos católicos para impedir el acceso al aborto y a las políticas de salud reproductiva en Argentina.

Este trabajo intenta ahondar en esta problemática describiendo la participación de un grupo de actores católicos en las cuatro audiencias públicas sobre la regulación de los procedimientos sanitarios en casos de aborto no punible convocadas por la comisión de salud de la Legislatura

\footnotetext{
2 Ver. SHEPPARD, Bonnie. The double discourse on sexual and reproductive rights in Latin America: the chasm between Public policy and private actions y NGO Advocacy Networks in Latin America: lessons from the experience in promoting women's and reproductive rights en SHEPPARD, Bonnie. Running the obstacle course to sexual and reproductive health: lessons from Latin America. Santa Barbara. Praeger Publishers. 2006, p. 13-98. ÁLVAREZ, Sonia et al. Encountering Latin American and Caribbean Feminisms. Journal of Women In Culture And Society, The University of Chicago, v. 28, n. 2, winter 2003, p. 537-579.
} 
de la Ciudad de Buenos Aires durante octubre y noviembre de 2008. Esta Legislatura es el Parlamento Local de la Capital Federal de la Argentina, el debate legislativo gira en torno a la reglamentación de un protocolo de atención sobre abortos no punible para ser aplicado en los hospitales de la Ciudad. La importancia de este debate radica en que por un lado es el primer debate público que se da- para el sistema político es casi imposible poner sobre la mesa este tema- $y$, por el otro porque los avances legislativos en la Ciudad surten un efecto simbólico sobre el resto de las comunas y también ejercen influencia sobre los legisladores nacionales. En materia de Salud Sexual y Reproductiva, la Legislatura de la Ciudad de Buenos Aires fue una de las primeras que sancionó una Ley de Salud Sexual y Reproductiva, en el año 2000, y a nivel nacional, esta legislación recién pudo sancionarse para el 2006.

Para realizar este trabajo se utilizan como material de análisis las observaciones realizadas en cada una de las audiencias y un corpus de 164 páginas de las versiones taquigráficas de las sesiones publicadas por la Legislatura de la Ciudad de Buenos Aires. ${ }^{3}$ En primer lugar se describen las características de los proyectos de ley presentados por los/as legisladores/ as de la Comisión. Luego, se profundiza en el perfil de de los expertos que participaron y se analizan sus exposiciones y recomendaciones a la comisión indicando los principales ejes del debate: el papel de los médicos y la objeción de conciencia, el "derecho a la vida" / "derecho del niño", los "derechos humanos" y la violación de las mujeres. Por último, se intenta plantear algunas herramientas de análisis, puntos de acuerdo y anclaje identitario de los participantes en el debate.

Se seguirá la línea teórica desarrollada por Juan Marco Vaggione, quien sostiene que las identidades religiosas tienen influencia sobre los debates legislativos a través de funcionarios y ciudadanos y que, por lo

3 Versiones taquigráficas disponibles en http://www.legislatura.gov.ar/vt.php. 
tanto, la religión es una dimensión interviniente en la sanción y aplicación de leyes más allá de las actividades particulares que lleven adelante las jerarquías católicas. (VAGGIONE, 2009, p. 3) En estos debates públicos convocados por la comisión de salud se evidencian dos procesos. Por un lado, además de impedir la regulación del aborto no punible en tanto valor doctrinario del catolicismo, está en juego la estrategia política adoptada por algunos actores católicos para imponer una visión legítima del mundo social (WAQCUANT, 2005, p. 16) que consolide la hegemonía simbólica de la Iglesia Católica en la regulación de la vida (y la muerte) de los individuos, especialmente de las mujeres. Por el otro, se pone en juego la hegemonía de los grupos que llevan adelante estas estrategias al interior de la Iglesia Católica. Una derrota en la arena pública implicaría establecer nuevos acuerdos entre las distintas comunidades y grupos que compiten por un lugar hegemónico al interior del catolicismo.

\section{Los/as legisladores/as y los proyectos}

Desde 2007, el gobierno de la Ciudad de Buenos Aires está presidido Mauricio Macri, jefe del partido PRO (Propuesta Republicana), una fuerza surgida a partir del año 2005, producto de la alianza de partidos de derecha locales y nacionales. A partir de los resultados electorales este partido obtuvo la Jefatura de Gobierno y mayoría parlamentaria en la Legislatura, los dos bloques opositores principales eran el Frente para la Victoria (del Partido Justicialista) y la Coalición Cívica (alianzas entre distintos partidos provenientes de la Unión Cívica Radical, el ARI y el socialismo). La plataforma de gobierno del PRO estaba dirigida principalmente a constituirse como oposición al Gobierno Nacional, liderado por el Frente para la Victoria del Partido Justicialista. En su agenda política se privilegiaban temas como la seguridad pública y la gestión del espacio público. Educa- 
ción y salud estaban en un segundo plano. La Salud reproductiva no era un eje central y, teniendo en cuenta las posturas conservadoras de los/as dirigentes de este partido, era esperable que el aborto no figurara en la agenda como problemática de salud pública.

Para 2008, la Comisión de Salud de la Legislatura estaba integrada por once legisladores/as cinco del PRO, una del Partido Justicialista (disidente del Frente para la Victoria), una por el Frente para la Victoria, tres de la Coalición Cívica y una por Diálogo por Buenos Aires (Partido liderado por el ex-jefe de Gobierno Aníbal Ibarra (período 2000-2006). La presidencia de la Comisión correspondía a Lidia Saya del PRO, la vicepresidencia $1^{\circ}$ a Alicia Bello del Frente para la Victoria y la vicepresidencia $2^{\circ}$ a Diana Maffia de la Coalición Cívica. En este contexto político, fueron convocadas reuniones públicas para debatir la manera de reglamentar los procedimientos médico-sanitarios en casos de aborto no punible en la Ciudad de Buenos Aires con el objetivo llegar a un acuerdo entre los cuatro proyectos de ley que se habían presentado. Los proyectos en discusión habían sido presentados por legisladores/as de la Comisión de Salud y otros que no pertenecían a ella. Se discutían los textos legislativos de los/ as diputados/as Juan Cabandié (Frente para la Victoria), Gabriela Alegre (Diálogo por Buenos Aires), Diana Maffia (Coalición Cívica) y Pablo Failde (Frente para la Victoria). Si bien los proyectos tenían la misma meta, la regulación de los procedimientos en casos de aborto no punible, se evidenciaban algunas diferencias en cuando al objeto explícito declarado por los/as legisladores/as para la sanción de esta ley, los requisitos para que los casos califiquen como de aborto no punible ${ }^{4}$ y los plazos en los

4 Cfr. Art. 86 Inc. 1 y 2 del Código Penal Argentino. El aborto practicado por un médico diplomado con el consentimiento de la mujer encinta, no es punible: 1) Si se ha hecho con el fin de evitar un peligro para la vida o la salud de la madre y si este peligro no puede ser evitado por otros medios; 2) Si el embarazo proviene de una violación o de un atentado al pudor cometido sobre una mujer idiota o demente. En este caso, el consentimiento de su representante legal deberá ser requerido para el aborto. 
cuales deberían practicarse. Las diferencias en los textos legislativos podrían enmarcarse en dos coordenadas, por un lado, la focalización en el derecho salud de las mujeres y por el otro en el aborto (no punible) como un efectivo derecho de las mujeres. En el caso del legislador Cabandié (Expediente 921-D-08) la motivación era "garantizar la salud integral de las mujeres" y propiciaba la interrupción del embarazo "en un plazo no mayor a tres días hábiles". La diputada Alegre (Expediente 1305-D08) auguraba por una "atención integral de los abortos no punibles" y la realización de los procedimientos quirúrgicos en un plazo de siete días "corridos". Pablo Failde (Expediente 1475-D-08) propiciaba "garantizar el derecho de las mujeres a la interrupción del embarazo en los casos de aborto no punibles" en hasta seis días y el proyecto de Diana Maffia (Expediente 1306-D-08) corría un tanto las fronteras de la discusión ya que su objeto manifiesto era "garantizar el acceso a esta práctica médica a las mujeres, las adolescentes y las niñas en edad fértil que soliciten la atención de su salud" interrumpiendo los embarazos "en el menor plazo posible, nunca mayor de diez días corridos." Las diferencias en cuanto a los plazos considerados correctos para la interrupción de un embarazo podría parecer un detalle menor, sin embargo, ayuda a comprender cuáles son las representaciones de estos/as legisladores/as a la hora de definir en qué momento el embrión puede llegar a ser viable y por tanto convertirse en persona. La cuestión del embrión considerado como persona y niño atravesará todas las discusiones en las audiencias públicas de la comisión de salud en cuanto a la regulación de estos procedimientos quirúrgicos.

Los proyectos tenían algunos consensos ya que los/as legisladores/as (autores/as) coincidían en la necesidad de evitar la judicialización y la intervención de comités de ética médica que demoraran los procedimientos. Las decisiones respecto a la efectiva interrupción o no de los embarazos deberían ser acordadas entre el médico interviniente y la 
paciente (o su representante legal). Por último, los proyectos estipulaban que cada médico que por convicciones personales no estuviera de acuerdo en practicar ningún tipo de aborto debería dejar constancia de su objeción de conciencia a título individual. Estos puntos fueron los más sensibles y fuertemente discutidos en la prensa nacional y publicaciones religiosas de los grupos católicos que observan y monitorean constantemente los desarrollos legislativos en materia de salud reproductiva. "Judicializar" y dar ingerencia a los comités de ética hospitalaria, liderados por médicos católicos, son las dos principales estrategias que desde fines de la década de 1990 comenzaron a utilizar ciertos grupos del catolicismo para impedir no sólo el efectivo acceso al aborto no punible en instituciones de salud pública sino también la implementación de políticas de salud reproductiva en el marco de "la agenda bioética en Argentina" ${ }^{5}$ Según el proyecto de ley de la diputada Alegre:

...se prohíbe la imposición de exigencias adicionales tales como la autorización de más de un profesional de la salud, la revisión o autorización por auditores, comités de ética, jueces $u$ otros operadores jurídicos, la imposición de períodos y listas de espera, el consentimiento de terceros, o cualquier otro trámite que pueda representar una carga desproporcionada para la mujer (Cfr. Exp. 1305-D-08. art. 2)

Así, un mes antes de comenzar las audiencias públicas abogados de una universidad confesional católica, líderes en la judicialización de casos de aborto en el país, se prepararon para participar del debate público y elaboraron un documento que distribuyeron entre colegas y algunos/

\footnotetext{
5 Esta estrategia quedó firme para el año 2002 cuando una ONG católica logró un fallo favorable de la Corte Suprema de Justicia de la Nación para la prohibición de la píldora de anticoncepción de emergencia (Ver Portal de Belén - Asociación Civil sin Fines de Lucro c/ Ministerio de Salud y Acción Social de la Nación s/ amparo," CSJN, 5 de marzo de 2002.). Para 2006, se estableció "La agenda bioética en Argentina". Ver Actas del III Congreso Internacional de bioética personalista. "La agenda bioética en Argentina", en Vida y Ética año 7 n², Universidad Católica Argentina, Buenos Aires, 12/13 de octubre de 2006.
} 
as diputados/as de la ciudad donde refutaban todos los artículos de cada uno de los cuatro proyectos:

A continuación se exponen algunas ideas jurídicas generales que son aplicables a todos y por último se comentan en el texto mismo de los proyectos las observaciones que tenemos para cada norma en particular (...)La locución "no es punible" implica -necesariamente-, que se trata de una excusa absolutoria; es decir que todo aborto es un hecho delictivo, pero por razones de política criminal, bajo determinadas condiciones -las taxativamente enumeradas en los incisos 1 y 2 [del código penal]-, no era penado... (Documento Anónimo "Opinión Proyectos de Aborto") ${ }^{6}$

\section{El contexto y los (des) encuentros}

Para sortear las diferencias, ampliar los consensos y obtener legitimidad para la regulación de los abortos no punibles en la Ciudad de Buenos Aires, la comisión legislativa convocó a veintiocho especialistas durante cuatro reuniones para que presenten su opinión y propongan modificaciones a los proyectos de ley presentados para reglamentar los procedimientos de aborto no punible en la Ciudad de Buenos Aires. Los especialistas eran médicos/as y abogados/as que cumplían funciones en algún organismo del Estado, en asociaciones de la sociedad civil, en universidades y el Consejo Nacional de Ciencia y Técnica. En las mesas de debate había especialistas mujeres y varones en iguales cantidades.

Al analizar los argumentos esgrimidos y las posiciones ideológicas asumidas por los participantes, se pudo detectar que del total de veintiocho especialistas invitados, doce eran católicos y uno evangélico experto

6 Tuve acceso al documento a partir de un informante clave de un grupo de especialistas católicos en derecho. En él se evidencian varios de los argumentos que los actores religiosos católicos expusieron en los debates públicos. 
en bioética de la Alianza Cristiana de Iglesias Evangélicas de la República Argentina (ACIERA). A excepción del presidente de la Corporación de Abogados Católicos, convocado por Enrique Olivera (Jefe del Bloque de la Coalición Cívica), ninguno fue invitado como actor religioso. Asistieron en su condición de profesionales: médicos/as y abogados/as docentes universitarios o miembros de organizaciones de la sociedad civil. Esto responde a una estrategia que Juan Marco Vaggione interpreta como secularización estratégica: los actores religiosos intervienen en el juego político con discursos más seculares que teológicos o religiosos (VAGGIONE, 2009, p. 13)7. Además de los expertos convocados por la comisión, al iniciar las sesiones se invitaba al público asistente a anotarse - voluntariamente - como oradores para manifestar su opinión. En el total de audiencias participaron diez y siete personas del público, ocho de los cuales eran militantes PRO VIDA (siete católicos y un evangélico de ACIERA), el resto eran militantes de partidos políticos de izquierda y miembros de organizaciones de derechos, a favor del aborto y de la diversidad sexual.

El proceso deliberativo estaba montado como estrategia dramatúrgica por parte de los/as legisladores/as autores de los proyectos para dar visibilidad al debate sobre aborto. El contexto en el cual se planificó el encuentro entre los actores fue un salón de la legislatura porteña ${ }^{8}$. Las cabeceras de la

7 A esta interpretación podría agregarse que muchos de los actores católicos que participan de los debates políticos son miembros del Opus Dei, una Prelatura Personal integrante de la Iglesia Católica que se caracteriza precisamente por ser "secular". Según sus datos, del total de sus miembros, el $98 \%$ son laicos y el $2 \%$ sacerdotes, es decir "están en el mundo ordinario". Su tarea pastoral se lleva a cabo en los espacios de la vida cotidiana en los que estos laicos participan. La mayoría son profesionales que cuentan con las más prestigiosas credenciales académicas y generalmente ocupan cargos jerárquicos tanto en empresas como en organismos del Estado. Para más información ver http://www.opusdei.org.ar

8 Según E. Goffman, los contextos son los espacios donde se producen los encuentros entre actores sociales. El encuentro es definido como la interacción entre individuos. Según el autor los individuos se comportan de manera distinta según los encuentros y representan distintos papeles. Ver GOFFMAN, Erwin. El individuo como unidad en GOFFMAN, E. Relaciones en Público. Microestudios del orden público. Madrid. Alianza, 1979, p. 23-46. Goffman, E. (1979 [1971]) 
mesa de debate estaban ocupadas por los/as legisladores/as de la comisión y los camarógrafos y cronistas de los principales medios masivos de comunicación. En el medio se ubicaban los especialistas. Alrededor de ellos el público, que a partir de sus sistemáticas manifestaciones, aplausos e insultos se pudo detectar que estaban ubicados en el espacio según afinidades ideológicas. De un lado, los actores religiosos católicos, en apariencia como un colectivo homogéneo y del otro, los activistas de los movimientos de derechos y partidos de izquierda. Cada uno de ellos portaba sus símbolos identitarios, por ejemplo, las mujeres que participan de la Campaña Nacional por el aborto legal y seguro llevaban pañuelos verdes al cuello y las mujeres y varones católicos remeras con consignas y rosarios.

Esta descripción cuantitativa de los asistentes y su ubicación en el espacio de interacción da una idea clara de las características que adquirió el contexto en el cual se debatían los proyectos de aborto no punible. Además permite ubicar con claridad las posturas ideológicas de cada uno de los participantes en el debate y detectar una racionalidad en la composición y elección de quienes se sentaron en la mesa junto con los/as diputados/ as para debatir. Al principio del proceso deliberativo se procuró mantener un " $50 \%$ y $50 \%$ ", la mitad de los especialistas a favor de la reglamentación del aborto no punible y la mitad en contra. Esto implicaba más bien una enunciación pública favorable o en contra del aborto en general.

La lógica del "50\% y 50\%" se veía reforzada en la expresión de los/as especialistas y participantes que cuando tomaban el micrófono hacían referencia a la existencia de "dos bandos", del debate como un partido de fútbol, un "Boca - River" que evidencia que cada uno de los que participó entendía que había rivalidades profundas ${ }^{9}$. Las palabras del Dr. Sylvestre Begnis, en

9 A medida que avanzaban las sesiones se veía la voluntad del público de participar para correr la balanza hacia uno u otro lado, como si el solo hecho de manifestar una opinión tuviera su correlato efectivo en el tratamiento de los proyectos. Así, sorteando la agenda organizada, en la primera reunión se presentó María José Lubertino, en ese entonces presidente del INADI, 
ese momento presidente de la comisión de salud de la Cámara de Diputados de la Nación, invitado como especialista, ilustran la lógica de los dos bandos:

Tengo una sola objeción a estas reuniones en las que ya he participado unas quince veces este año: nos encontramos los que militamos una u otra posición, pero siempre somos los mismos. Pareciera ser que es el futuro no deseado de estas reuniones, ya que no nos vamos a convencer el uno al otro, dado que partimos de premisas y concepciones distintas, y asignamos el derecho, probablemente, de manera distinta". (Sylvestre Begnis, audiencia pública de la comisión de salud de la Legislatura de la Ciudad de Buenos Aires, 31/10/08).

A medida que ingresaban al recinto, espacio definido que los individuos pueden reivindicar temporalmente (GOFFMAN, 1979, p. 50), los actores se iban reconociendo. La presencia de figuras como Nelly Minyersky, profesora consulta de la Universidad de Buenos Aires que en la actualidad investiga sobre "derechos humanos en la democracia desde una perspectiva bioética"10 y Alberto Solanet, presidente de la corporación de abogados católicos de Argentina, organización que en la actualidad también trabaja cuestiones de bioética, confirman la percepción de los participantes en este debate: ya se han encontrado en otras discusiones públicas defendiendo posturas contrarias. Minyersky y Solanet pertenecen a la misma generación, los dos son abogados graduados a principios de 1960, se especializaron en derecho civil y derecho de familia y, desde la apertura democrática, participan activamente en todos los debates públicos sobre cuestiones de familia. Ambos tuvieron un rol activo, desde la sociedad civil, en el momento de la sanción de la ley de

que abrió la sesión con un amplio discurso a favor de la reglamentación y, también estuvo presente la diputada del PRO Victoria Morales Gorleri, católica Pro Vida, que se encargó especialmente de cuestionar los argumentos Mariana Romero, investigadora del CONICET y miembro del CEDES, la única científica de la mesa.

10 Cfr. Secretaría de Ciencia y Técnica de la Nación. Disponible online en: http://www.sicytar. secyt.gov.ar/busqueda/prc_imp_cv_int?f_cod=0000814695. 
divorcio a fines de la década de 1980: Las resistencias y la hipocresía que existen hoy frente al tema [del aborto] me hacen recordar en cierto modo a las que hubo cuando promovíamos y peleábamos por la ley de divorcio vincular $^{11}$ (Minyersky, 13/9/2009). Minyersky alude recordar el momento de discusión sobre el divorcio y también Solanet ya que el aborto, según su postura y la de su grupo, es consecuencia de la "degradación de la familia tradicional producto del triunfo del relativismo, la ideología de género y la cultura de la muerte" (SCALA, 2006, p. 14) que triunfó en Argentina a partir del restablecimiento de la democracia en 1983.

Cuando los participantes se encuentran se identifican personalmente recurriendo a los recuerdos que cada uno de ellos tenga de haber visto al otro previamente en un contexto diferente. Este conocimiento mutuo establece un marco que organiza y retiene la experiencia e implica para cada uno de los participantes la atribución, por parte del otro, a una identidad social específica (GOFFMAN, 1979, p. 195-196). El pasado aparece y se reconfigura remontándose a otros acontecimientos en los cuales se han encontrado en veredas distintas. En este proceso de hacer memoria se logra la autodefinición y la diferenciación de otros, constituyéndose como grupo - homogéneamente imaginado- a partir del trabajo de memoria (HERVIEU LEGER, 1996). En este debate de aborto no punible se reactualizan y cobran nuevos significados distintas concepciones sobre la nación, la democracia y la historia reciente ${ }^{12}$.

11 Entrevista a Nelly Minyersky en Pagina 12, 13/9/2009. Disponible online en: http://www. pagina12.com.ar/diario/sociedad/3-131677-2009-09-13.html.

12 La lógica de "los dos bandos" cobra un nuevo sentido cuando se analizan las manifestaciones a favor de la dictadura militar de 1976 de los actores católicos que participaron de este debate legislativo. El presidente de la Corporación de Abogados Católicos cree que hubo una guerra que adquirió una intensidad sin precedente. Diariamente ocurrían homicidios, secuestros, usurpaciones, asaltos y otros gravísimos delitos y que con la democracia se forjó una visión asimétrica y unilateral del último medio siglo, en la que los agresores de la sociedad civil quedaron transformados en "jóvenes idealistas" que habían sido injustamente perseguidos. Solanet, A. El Bicentenario y la pacificación nacional. La Nación 15/4/2009 disponible en http:// www.lanacion.com.ar/nota.asp?nota_id=1118392. 


\section{Los ejes del debate: ¿derecho de quién?}

Todos los participantes al exponer sus argumentos hacían mención a que se estaba discutiendo una cuestión de derechos, las diferencias emergen a la hora de explicitar quién sería el sujeto de derecho en cuestión. En principio, si bien desde lo formal en los textos de los proyectos se hacía alusión a la salud de las mujeres, en tanto un derecho a respetar, los ejes centrales del debate fueron el papel de los médicos y la objeción de conciencia, el "derecho a la vida" / "derecho del niño", los "derechos humanos" y la violación de las mujeres. Una minoría de participantes hizo alusión la falta de acceso al aborto no punible como un caso de violencia contra las mujeres, incorporando al debate cuestiones como el "derecho a decidir" o los derechos reproductivos. Todos los temas tratados adquirieron significados distintos según quien los enunciaba y en general estaban cargados de un contenido biológico y, a la vez, religioso. La discusión en torno a los derechos del "niño" quedó habilitada desde los textos legislativos porque emergían concepciones distintas acerca de la viabilidad de los embriones. La necesidad legal de poner un plazo temporal (semanas o días) para la efectiva realización de los procedimientos quirúrgicos devela, como una representación general de los parlamentarios, que a partir de cierto momento el embrión se convierte en una entidad a tutelar. ¿Qué diferencias hay entre tres o cuatro días hábiles o corridos? ${ }^{13}$ En repetidas oportunidades los actores religiosos propusieron argumentos biológicos y genéticos para demostrar que cuando hay "ADN humano" se está en la presencia de un individuo de la especie humana y por tanto de una per-

13 Sobre el inicio de la vida humana hay distintos puntos de vista. En este debate se traslucía la concepción de que la vida se inicia en la fecundación, punto de inicio de un proceso de división celular durante la gestación. Ver VÁZQUEZ, Rodolfo. La cuestión del embrión y algunos problemas de la bioética en PÉREZ TAMAYO, Ruy, LISKER, Rubén y TAPIA, Ricardo. La construcción de la bioética, v. 1, FCE, México, 2007. 
sona que tiene derechos humanos. Además, interpelaban a los/as diputados/as para que sentaran su posición respecto a cuándo consideraban que se iniciaba la vida. Los/as legisladores/as siempre accedían a responder:

No tiene nada que ver, es decir, no significa que no exista vida el hecho de que haya una distinta pena por la muerte de un chico nacido, o por un chico no nacido, o por un chico que no tenga orejas. ¿Me explico? No es la intensidad de la pena, no significa que el sujeto o la víctima tenga vida o no tenga vida. ¿Me explico, o no? (Diputado Aníbal Ibarra, Audiencia Pública Comisión de Salud de la Legislatura de la Ciudad de Buenos Aires, 3/10/08)

Los actores religiosos ocuparon el papel de los portavoces de la defensa de los derechos humanos: toda norma que trate de la vida humana automáticamente convoca la atención de los organismos de derechos humanos y compromete a la protección de todos ellos. (Mario Turzi, Audiencia Pública Comisión de Salud de la Legislatura de la Ciudad de Buenos Aires, 3/10/08). La referencia a la "atención de los organismos de derechos humanos" refiere a la atención de las organizaciones de católicos, que sistemáticamente se presentan públicamente como parte del colectivo de organismos defensores de los derechos humanos. La presentación que la presidenta de la Comisión hizo de Mario Turzi ilustra esta significación:

El doctor Turzi tiene un amplio currículum, que voy a sintetizar. Es abogado, egresado de la Universidad de Buenos Aires y participa en diversas organizaciones nacionales e internacionales. Preside la Comisión de Control Constitucional de la Defensoría de la Vida Humana, una organización argentina que integra una red mundial de entidades de derechos humanos. (Diputada Alicia Bello - Frente para la VictoriaAudiencia Pública Comisión de Salud de la Legislatura de la Ciudad de Buenos Aires, 3/10/08) 
El argumento esgrimido se retrotraía al espíritu mismo de la Declaración Universal de DDHH de 1948:

La Declaración Universal de los Derechos del Hombre de 1948 -la semana próxima vamos a conmemorar esta fecha en el Senado- sostiene que el derecho a la vida se le debe reconocer a todas las personas por el solo hecho de ser humanos, y no por otra razón (Úrsula Basset, especialista en derecho y bioética de la UBA y la Universidad Austral, Audiencia Pública Comisión de Salud de la Legislatura de la Ciudad de Buenos Aires, 31/10/08).

Al poner sobre la mesa el "espíritu de la Declaración" se estaba haciendo referencia, en una línea de continuidad histórica, a las políticas eugenésicas del nacional-socialismo alemán con la regulación del aborto no punible en la Ciudad de Buenos Aires y la despenalización del aborto en general. En este debate público los actores católicos, de distintas corrientes, equipararon el aborto al nazismo y al terrorismo de estado. ${ }^{14}$ Uno de los argumentos más elaborados en este sentido fue el de la Doctora Úrsula Basset que se refirió al establecimiento de un Estado de Excepción, haciendo referencia a la teoría de Carl Schmitt y a la configuración del embrión como homo sacer" ${ }^{15}$. Con la idea de "si hay ADN humano hay derechos humanos" los actores religiosos fueron planteando argumentos

14 Este argumento se encuentra en una homilía de 1976 del obispo de la Iglesia Católica Enrique Angelelli "Cómo se mata la vida" (mensaje de cuaresma).

“Cuando el 'guerrillero' nos sorprende con su cuota de muerte. Cuando las fuerzas 'custodias del orden' nos sorprenden también con su cuota de muertes. Cuando 'otras fuerzas ocultas' también nos sorprenden a diario con su cuota de muertes. Cuando se mata a los niños antes de nacer. Cuando mueren los niños por falta de pan y de medicamentos. Cuando se 'roba' el pan de los hogares y se 'vacía' de 'bienes' el país. Cuando nos enriquecemos con 'la sangre', del pobre, del débil, del 'sin voz' (...) Sólo Dios es Dueño de la Vida" En BARONETTO, Luis Miguel. El Martirio. En Vida y Martirio de Mons. Angelelli, Obispo de la Iglesia Católica. Córdoba: Ediciones Tiempo Latinoamericano, 2006, p. 177-242.

15 Ver AGAMBEN, G. Homo Sacer. El poder soberano y la nuda vida. Valencia: Pre Textos, 1999. 
en el que convergieron elementos principalmente biológicos y luego, jurídicos y religiosos. Los argumentos jurídicos estaban basados en una minuciosa lectura e interpretación de los tratados internacionales y los códigos penal civil y penal de la Argentina. A partir de la impronta biológica que adquirió el debate se pudo trasladar el foco hacia el embrión, considerado como persona y niño. Tan fuerte era la postura de los actores religiosos en cuanto defensores de los derechos humanos que una de las especialistas en bioética invitada, durante su exposición, tuvo que aclarar

...estos son temas que pertenecen y que pueden discutirse también desde una perspectiva del derecho internacional, pero también desde la perspectiva ética que implica los derechos humanos de las personas y de las mujeres involucradas... (Florencia Luna, especialista en bioética FLACSO, Audiencia Pública Comisión de Salud de la Legislatura de la Ciudad de Buenos Aires, 31/10/08)

Las personas involucradas en el debate y, por tanto, objeto de la futura ley eran "los niños" y "los médicos". Las palabras de Ricardo Bach de Chazal ilustran el argumento de los actores religiosos respecto a los niños:

Nuestro Artículo 75, inciso 22, dispone que estos tratados, en las condiciones de su vigencia, tienen jerarquía constitucional. Entonces, tenemos que la condición de vigencia que manda a respetar el derecho de la vida del niño desde la concepción tiene esa jerarquía, superior al Código Penal y derogatoria de éste. Es más, el Artículo $3^{\circ}$ de la Convención expresa que, en caso de duda, siempre debe optarse por el interés superior del niño, y lo mismo repite nuestra Ley Federal 26.061, en su Artículo 30, cuando sostiene que debe ser preferido el derecho del niño a toda otra aspiración, derecho o interés legítimo. (Ricardo Bach de Chazal, abogado, especialista en derecho penal e internacional, Audiencia Pública Comisión de Salud de la Legislatura de la Ciudad de Buenos Aires, 31/10/08). 
"Los médicos" eran una de las principales preocupaciones y ocuparon gran parte de las discusiones. Los cuatro proyectos de ley en discusión incorporaban artículos sobre la objeción de conciencia, un recurso al cual recurren los profesionales de la salud para no practicar abortos (no punibles) en hospitales públicos ${ }^{16}$. En los textos legislativos se indicaba que a partir de la sanción de la ley cada médico del sector de ginecología debía entregar a la dirección de su hospital una declaración escrita en la cual dejara constancia de su objeción de conciencia a título individual. Con la declaración de la objeción de conciencia, el Estado podría garantizar el acceso al aborto (no punible) a las mujeres ya que quedaba estipulado que todas las instituciones deberían realizar los procedimientos reemplazando a los objetores por aquellos profesionales que aceptaran realizar las interrupciones de embarazos (Cfr. Expte. 1306-D-08 art. 9).

Finalmente -y éste es un derecho de cualquier pacientedebe informarse a la mujer, en el momento en que solicita la atención, que el profesional que la está atendiendo es objetor de conciencia y que tiene la obligación de derivarla a un profesional que sí cumpla con las necesidades y con los servicios que esa mujer está requiriendo (Mariana Romero, Audiencia Pública Comisión de Salud de la Legislatura de la Ciudad de Buenos Aires, 3/10/08)

16 Desde la Academia Pontificia para la Vida el Vaticano se exhorta a los laicos en general, no sólo a los profesionales de la salud, a recurrir a la objeción de conciencia "Las exigencias específicas de la conciencia cristiana se ponen especialmente a prueba en el caso de los profesionales de la salud, cuando se hallan ante el deber de proteger la vida humana y corren el peligro de verse implicados en situaciones de cooperación con el mal al cumplir sus deberes profesionales. En esta situación cobra mayor relieve la obligación de recurrir a una "valiente objeción de conciencia", que tienen médicos, enfermeros, farmacéuticos y personal administrativo, jueces y parlamentarios, y otros profesionales directamente implicados en la defensa de la vida humana individual, donde las normas legislativas prevean acciones que la pongan en peligro." (Crf. DECLARACIÓN FINAL DE LA XIII ASAMBLEA GENERAL, ACADEMIA PONTIFICIA PARA LA VIDA 2007, disponible en: http://www.vatican.va/roman_curia/pontifical_academies/acdlife/documents/rc_pont-acd_life_doc_20070315_xiii-gen-assembly-final_sp.hẗml). 
Los actores religiosos recurrieron como argumento de la discriminación de los médicos por sus convicciones para rechazar la medida:

En los hospitales va a existir un formulario para el ginecólogo que quiera ingresar. Una de las preguntas será: "¿Haría usted un aborto?". Si el postulante contesta "no", no entra; y si el postulante contesta "si", se verá obligado a efectuar una práctica en contra de su conciencia (...) Esto es algo que los ginecólogos no aceptamos" (Salvador Romano, Audiencia Pública Comisión de Salud de la Legislatura de la Ciudad de Buenos Aires, 14/11/08)

En segundo lugar, quería decir respecto de la otra hipocresía a la que se refería el diputado Ibarra que, casualmente -sé que no puedo aludir, pero no sé cómo decirlo- la Presidenta del INADI, dijo que aquellos médicos que no quieran practicar abortos se podían anotar en una lista. ¿Hay algo más discriminatorio que una lista de este tipo? ¿Hay algo que amedrente más, que esta lista? Todo es secreto, pero si no querés hacer un aborto tenés que anotarte en esta lista para que no te expulsemos del trabajo" (María Eugenia Farías, Audiencia Pública Comisión de Salud de la Legislatura de la Ciudad de Buenos Aires, 17/10/08)

A medida que avanzaba el debate quedaban en evidencia las estrategias "bioéticas" que tienen ciertos grupos católicos: judicializar, dar intervención a los comités de ética y hacer uso de la objeción de conciencia para impedir el efectivo acceso de las mujeres a las políticas de salud reproductiva. Antes de este debate público estas estrategias estaban invisibilizadas, por ello los argumentos presentados indican que los católicos que se presentaron a discutir tenían un especial interés en que estas estrategias permanezcan sin ser objeto de regulación para seguir garantizando su eficacia práctica. 


\section{La inevitabilidad de la violación de las mujeres}

La violación de las mujeres, como temática, ocupó gran parte de los debates llegando sustituir la discusión formal sobre los procedimientos de aborto. Se discutieron los requisitos del inciso 2 o del artículo 86 del código penal: el aborto no es punible si el embarazo proviene de una violación o de un atentado al pudor cometido sobre una mujer idiota o demente. Las palabras de la legisladora Diana Maffia, autora de uno de los proyectos, pusieron en alerta a los participantes del debate: que toda mujer que ha sufrido una violación no tenga, como consecuencia, que llevar adelante un embarazo no deseado (Diana Maffia, Audiencia Pública Comisión de Salud de la Legislatura de la Ciudad de Buenos Aires, 3/10/08). Esta expresión, manifestada en la primera audiencia pública, fue interpretada por los actores religiosos como un interés de la legisladora por modificar directamente el artículo del Código Penal y por ello argumentaron en reiteradas oportunidades que la Legislatura de la Ciudad, en tanto entidad local, no era un ámbito competente para discutir esta temática.

Tomando este contexto, quiero precisar también el ámbito de la discusión, porque se dijo que la Legislatura no tiene ciertas facultades. En realidad, no estamos debatiendo la no punibilidad del aborto, lo cual corresponde al ámbito nacional. Lo que esta Legislatura está tratando de hacer es regular procedimientos que habiliten o, dicho de otra manera, que la ausencia de dichos procedimientos no impidan la ejecución de abortos no punibles por el Código Penal. Es decir, ya está establecido que no son castigados por el Código Penal. Esto es bien distinto. Podríamos generar una discusión -sería muy bueno- sobre la punibilidad o no del aborto en general, lo cual corresponde al ámbito nacional. A nadie se le ocurre que nosotros vamos a legislar sobre eso, porque es facultad del Congreso Nacional para toda la Argentina (Aníbal Ibarra, Audiencia Pública Comisión de Salud de la Legislatura de la Ciudad de Buenos Aires, 3/10/08). 
En un amplio sector de los defensores de la regulación de los procedimientos de aborto, la violación sexual de las mujeres se convirtió en principal argumento esgrimido para dar legitimidad al acceso al aborto. De las expresiones de la mayoría de los participantes del debate emergen representaciones que hacen alusión a la inevitabilidad de que las mujeres sean violadas (en el espacio público), a la violación como "desgracia"17 y a la imagen del violador como un animal solitario. Las palabras de uno de los legisladores autores de un proyecto de ley ilustran esta percepción:

Podríamos emparentar al hombre y al perro: todos vimos el accionar de algún perro por ahí, ya sea vagabundo, callejero, un perro de raza, o "raza perro". El perro va por la calle, ve a una perra que está en celo y, 'pum', relación coital. Sale de esa perra, va para otro distrito -acá no hay pertenencia territorial-, camina, camina, ve a una perra que está en celo -quizás, ésta le ladra o le muerde una oreja porque no quiere- $y$, 'pum', relación coital. $Y$ así puede hacerlo en el día las veces que quiera, según le dé la energía y según si está bien alimentado, pobre perrito. (...) Imaginemos si el hombre tuviera la misma actitud o hiciera las mismas cosas." (Juan Cabandié, Audiencia Pública Comisión de Salud de la Legislatura de la Ciudad de Buenos Aires, 31/10/08).

El legislador intentaba refutar los argumentos de los actores religiosos que se referían al violador como un "padre": indicaban que el violador esta-

17 La Doctora Galimberti, Directora del Hospital Álvarez ilustra este razonamiento: “La verdad es que los medios de comunicación fueron el elemento fundamental para que la gente se entere de que si tiene la desgracia de ser violada debe ir al hospital lo antes posible, para poder hacer el tratamiento correspondiente. Al respecto, les cuento que hubo tres embarazos. Uno de los casos es el de una niña de 12 años, violada por un tío. Aclaro que en el caso de menores interviene el Consejo de Niños, Niñas y Adolescentes. Pero quiero señalar algo: lo que a veces las mujeres suponemos, no tiene la misma perspectiva. Es decir, en los tres casos -y aún en el de la nenita de 12 años-, se preguntó y se entrevistó a las víctimas y ninguna decidió pedir la interrupción del embarazo." (Diana Galimberti, audiencia pública de la Comisión de Salud de la Legislatura de la Ciudad de Buenos Aires, 31/10/08). 
ría otorgando la gracia de la maternidad a las mujeres. ${ }^{18} \mathrm{El}$ proyecto - como también lo dijimos - extiende la impunidad [de las mujeres] a todos los casos en que el embarazo se haya producido por una supuesta violación. Se hace pagar así al niño la falta de su padre" (Alberto Solanet, Audiencia Pública Comisión de Salud de la Legislatura de la Ciudad de Buenos Aires, 3/10/08).

Además del reconocimiento de la paternidad del violador como un valor positivo algunos católicos equiparaban el texto del código penal "mujer idiota o demente" a "mujer discapacitada":

Muchas veces sucede que las personas discapacitadas que quedan embarazadas tienen una relación afectiva con personas que, en principio, parecieran agraviar su libertad sexual. A veces, incluso con las parejas de las madres o con otras personas. Como la afectividad esta bastante poco limitada por lo que nosotros llamamos el Superyó, por una categoría moral o por discriminaciones diversas, muchas veces tienen relaciones afectivas $y$, probablemente, muchas veces quisieran tener a sus hijos. Entonces, ipor qué presumimos Ique quieren interrumpir el embarazo]? Porque como no tienen libertad para consentir, existe -ustedes saben- la presunción de que cualquier abordaje sexual sobre ellas es contado como violación." (Úrsula Basset, Audiencia Pública Comisión de Salud de la Legislatura de la Ciudad de Buenos Aires, 31/10/08).

Los actores religiosos indicaban que si la mujer "idiota o demente" está imposibilitada para consentir relaciones sexuales entonces también está imposibilitada para consentir cualquier cosa, especialmente la interrupción de un embarazo. En este sentido utilizan argumentos tales como la "doble violación": luego de ser violada, la mujer - idiota - es violada

18 Sobre la maternidad y la vocación de las mujeres ver MULIERIS DIGNITATEM, Carta apostólica de Juan Pablo II (1988) Disponible en http://www.vatican.va/holy_father/john_paul_ii/ apost_letters/documents/hf_jp-ii_apl_15081988_mulieris-dignitatem_sp.html. Sobre la violación y la paternidad ver Otro caso testigo para forzar la legislación del aborto en NOTIVIDA Año VIII, no 543, 4 de septiembre de 2008 y Solanet, A. et al (2008) Abogados católicos contra posible aborto en Mendoza en NOTIVIDA, Año VIII, no 542. 
nuevamente porque no se le permite emitir opinión respecto a si continuar o no con el embarazo producto de la "primera" violación. Este razonamiento se basa también en la interpretación jurídica de los "casos violación o atentado al pudor de la mujer idiota o demente" como "excusas absolutorias" o "regímenes de excepcionalidad".

Así, los actores católicos que participaron del debate lograron imponer sus argumentos en la discusión derivando la conversación del procedimiento médico-sanitario a cuestiones más filosóficas y trascendentales. Obligaron a los legisladores a sentar su posición respecto a los motivos que justificaban sus propuestas a favor del aborto y dejaron en evidencia que hay ciertos puntos de anclaje identitarios comunes. Haciendo presión sobre la existencia de un embrión-niño-persona lograron que algunos legisladores expresaran que se "podía estar ante la presencia de un conflicto de derechos" entre el embrión-niño-persona y la mujer no persona que no quiere ser madre:

Para dar un ejemplo, el Código Penal establece la inimputabilidad cuando se actúa en legítima defensa y hay dos vidas en juego. En ese caso, también lo autoriza porque hay un conflicto entre dos vidas. Entonces, no es una cuestión absolutamente intocable; no. El propio Código Penal lo establece y le podría nombrar muchísimas más situaciones (Aníbal Ibarra, Audiencia Pública Comisión de Salud de la Legislatura de la Ciudad de Buenos Aires, 3/10/08).

Luego de este espectáculo de debate público los/as legisladores elaboraron dos dictámenes. Uno por la mayoría, que recomendaba aprobar un proyecto de ley consensuado sobre la base del de la diputada Maffia y otro por la minoría, que recuperaba los argumentos de los actores religiosos católicos y solicitaba archivar los proyectos. Enviaron estos dictámenes a la comisión de "mujer y familia" donde estuvieron un año más discutiendo y donde la presencia de diputadas católicas fue crucial para frenar el avance en el debate. Por último, a fines de 2009 la discusión se trasladó a la comisi- 
ón de Justicia. Los actores católicos que diseñaron la estrategia de participación en el debate parlamentario tienen la esperanza (y la certeza) de que los proyectos de ley sobre la reglamentación de los procedimientos de aborto no punible perderán estado parlamentario y no podrán ser debatidos por el conjunto de los/as legisladores de la Ciudad de Buenos Aires.

\section{Consideraciones finales}

Tendiendo en cuenta los ejes y el carácter que adquirieron las audiencias públicas en la Comisión de Salud, se observa que debatir sobre aborto implicaba reivindicar el monopolio de la violencia legítima sobre el cuerpo de las mujeres. Según Goffman (1979, p. 56), una reivindicación es sostenida por actores o grupos de actores que se disputan el derecho de poseer, controlar, utilizar y transferir el bien reivindicado. Los actores católicos se presentaron al debate público para defender su visión del mundo que les otorga un derecho (natural) a controlar, administrar y gestionar los cuerpos de las mujeres. Participar en un debate parlamentario y cargarlo de contenido católico implica una victoria simbólica sobre el "relativismo moral" y por tanto garantiza mantener el status quo entre las distintas comunidades y grupos que compiten por un lugar hegemónico al interior del catolicismo. Quienes llevan adelante estas estrategias son feligreses católicos que se congregan en comunidades de fuerte anclaje identitario. A lo largo de su trayectoria personal han atravesado distintos procesos de educación formal e informal afianzándose en una carrera militante (GIMÉNEZ BÉLIVEAU, 2007, p. 32) que complementan con prestigiosas credenciales académicas Para llevar adelante sus reivindicaciones legitiman su acción anclando su identidad en el mito de "la nación católica", aquel momento de la historia Argentina, iniciado en la década de 1930, donde el catolicismo adoptó un modelo aglutinador y centrali- 
zador que logró introducirse en todos las capas del Estado (MALLIMACI, 2008 , p. 5). Con su participación en la arena pública reviven con nostalgia aquel momento histórico y se proponen como la vanguardia que reinsertará los valores católicos al Estado - desde sus leyes - y por tanto a toda la sociedad civil.

Es importante resaltar que a partir de esta experiencia estos actores católicos continuaron profundizando su estrategia de participación de debates parlamentarios. Luego de la Ciudad de Buenos Aires expusieron sus ideas sobre la fecundación in vitro en la Cámara de Diputados de la Nación. Y, a partir del relativo éxito que tuvieron estas estrategias se incorporó la temática "Bioderecho. Bioética en el parlamento y en organismos internacionales" como contenido de estudios en los cursos de posgrado de las universidades pontificias de Argentina.

A partir de la observación de la presencia de estos actores en las audiencias públicas de la Legislatura de la Ciudad de Buenos Aires se puede afirmar que es necesario seguir profundizando en las configuraciones actuales de la participación política de estos militantes desde una mirada que rescate la complejidad y la heterogeneidad dentro del catolicismo. En futuros trabajos se intentará dar cuenta con mayor profundidad del proceso de consolidación hegemónica al interior del catolicismo que se juega en el espacio público. Este fenómeno es posible debido a que uno de los rasgos constitutivos de lo religioso es su desplazamiento hacia el terreno político y de éste hacia el religioso (CUCCHETTI, 2005, p. 15). 


\title{
The debate on abortion rights: the involvement of Catholic groups in the Health Committee of the Buenos Aires Legislature
}

\begin{abstract}
This paper discusses the participation of Catholic groups, specialized in bioethics and biolaw, in parliamentary debates on non-punishable abortion, in the Health Committee of the City of Buenos Aires, in late 2008. Taking into account the multiple transfers and influences between the political and the religious spheres in Argentina, the article examines the political strategy that certain actors of Catholicism use to consolidate the symbolic hegemony of the Catholic Church by regulating the life of individuals, especially women; and the use of these strategies as a way to maintain their hegemonic position within the Catholic Church.
\end{abstract}

Keywords: Bioethics. Biolaw. Abortion rights. Women and abortion.

\section{Referencias}

ÁLVAREZ, Sonia et al. Encountering Latin American and Caribbean Feminisms. Journal of Women In Culture And Society. The University of Chicago, v. 28, n. 2, winter 2003, p. 537-579.

AGAMBEN, Giorgio. Homo Sacer. El poder soberano y la nuda vida. Valencia: Pre Textos, 1999.

ARGENTINA. Audiencia Pública. Comisión de Salud. 3 de Octubre de 2008. Legislatura de la Ciudad Autónoma de Buenos Aires. Versión Taquigráfica.

. Audiencia Pública. Comisión de Salud. Legislatura de la Ciudad Autónoma de Buenos Aires. 17 de Octubre de 2008. Versión Taquigráfica.

. Audiencia Pública. Comisión de Salud. Legislatura de la Ciudad Autónoma de Buenos Aires. 31 de Octubre de 2008. Versión Taquigráfica.

. Audiencia Pública. Comisión de Salud. Legislatura de la Ciudad Autónoma de Buenos Aires. 14 de Noviembre de 2008. Versión Taquigráfica.

. Código Penal de la República Argentina. Buenos Aires: Errepar, 2009. 
ARGENTINA. Despacho de Mayoría Comisión de Salud. Ref. Exptes № 921 D-08, 1305-D-09, 1306-D-09 y 1475-D-09. Legislatura de la Ciudad de Buenos Aires.

. Despacho de Minoría Comisión de Salud. Ref. Exptes № 921-D-08, 1305-D-09, 1306-D-09 y 1475-D-09. Legislatura de la Ciudad de Buenos Aires.

. Proyecto de Ley. Procedimiento para la atención integral de los abortos no punibles en el sistema de salud de la Ciudad Autónoma de Buenos Aires. Diputada Gabriela Alegre. Expediente 1305-D-08.

. Proyecto de Ley. Procedimiento para el aborto en los casos no puni-

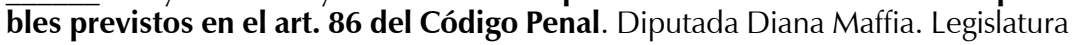
de la Ciudad de Buenos Aires. Expediente 1306-D-08.

. Proyecto de Ley. Procedimiento en casos de aborto no punible. Diputa-

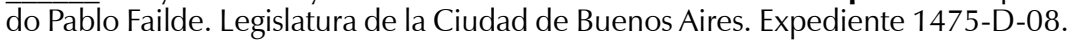

. Proyecto de Ley. Regulación del procedimiento para la atención y práctica de abortos no punibles. Diputado Juan Cabandié. Legislatura de la Ciudad de Buenos Aires. Expediente 921-D-08.

BARONETTO, Luis Miguel. El martirio. En vida y martirio de Mons. Angelelli, obispo de la Iglesia Católica. Córdoba: Ediciones Tiempo Latinoamericano, 2006, p. 177-242.

CONGRESSO INTERNACIONAL DE BIOÉTICA PERSONALISTA, III, 2006. La agenda bioética en Argentina. In: Vida y Ética, año 7, n. 2. Universidad Católica Argentina, Buenos Aires, 2006.

CORREA, Sonia. Aborto na cena política global: fios de história, desafios do momento en Ipas. Revista de salud sexual y reproductiva, n. 18, 2004, p.1-15.

CRUZ-COKE, Ricardo. Fundamentos genéticos del comienzo de la vida humana. In: Revista Chilena de Pediatría, v. 51, n. 2, 1980, p. 121-124. Disponible en: http://www.scielo.cl/pdf/rcp/v51n2/art06.pdf. Consulado en: 26 de enero de 2010.

CUCCHETTI, Humberto. Religión y política en Argentina y en Mendoza, 19431955. Lo religioso en el primer peronismo. Documento de trabajo n. 13, Buenos Aires, CEIL-PIETTE/CONICET, 2005.

DONATELLO, Luis. Sobre algunos conceptos para comprender las relaciones entre religión y guerrilla en la Argentina de los '60 y '70. Nuevo Mundo Mundos Nuevos, Debates [Online], 2008. Disponible en: http://nuevomundo.revues.org/ index38972.html. Consultado el 11 Febrero 2010.

GOFFMAN, Erwin. El individuo como unidad. In: GOFFMAN, E. Relaciones en Público. Microestudios del orden público. Madrid: Alianza, 1979, p. 23-46. 
GOFFMAN, E. Los territorios del yo. Relaciones en Público. Microestudios del orden público. Madrid: Alianza, 1979, p. 47-78.

GOGNA, Mónica. Estado del arte. Investigación sobre sexualidad y derechos en Argentina (1990-2002). Buenos Aires: CEDES, 2005.

FRASER, Nancy. Heterosexismo, falta de reconocimiento y capitalismo: una respuesta a Judith Butler. New Left Review. Mayo/Junio, 2000, p. 123- 136.

GIMÉNEZ BÉLIVEAU, Verónica. Carreras militantes. Comunidades católicas y formación de los sujetos en Argentina. Ciencias Sociales y Religión, n. 9. Porto Alegre: ACSRM/ UFRGS, 2007, p. 31-58.

GUTIÉRREZ, María Alicia. Silencios y susurros: la cuestión de la anticoncepción y el aborto. In: CÁCERES, Carlos F; FRASCA, Timothy; PECHENY, Mario; TERTO JÚNIOR, Veriano. (Orgs.) Ciudadanía sexual en América Latina: abriendo el debate. Lima: Universidad Peruana Cayetano Heredia, 2004, p. 129-140.

HEILBORN, María.; PETRACCI, Mónica; VIVEROS, Mara. Heterosexualidades, contracepción y aborto. Rio de Janeiro: CLAM, 2008, p.1-24.

HERVIEU-LÉGER, Danièlle. Catolicismo: el desafío de la memoria. In: Sociedad y religión, n. 14-15. Buenos Aires: CEIL-PIETE, 1996, p. 9- 28.

MALLIMACI, Fortunato. Nacionalismo católico y cultura laica en Argentina. In: BLANCARTE, Roberto (Coord.) Los retos de la laicidad y la secularización en el mundo contemporáneo. México, DF: El Colegio de México, 2008.

MINYERSKY, Nelly. La hipocresía con el aborto es como antes con el divorcio [set. 2009]. Entrevistadora: M. Carbajal. Entrevista para el diario Página 12. Disponible en : http ://www.pagina12.com.ar/diario/sociedad/3-131677-2009-09-13. html.

PECHENY, Mario. Yo no soy progre, soy peronista: ¿Por qué es tan difícil discutir políticamente sobre aborto? Ciudadanía sexual. Buenos Aires, 2005. Disponible en: www.ciudadaniasexual.org.ar. Consulado en 8 de Febrero de 2010.

PECHENY, Mario; PETRACCI, Mónica. Argentina: sexualidad y derechos humanos. Horizontes Antropológicos, año 12, n. 26, 2006, p. 43-69.

PETRACCI, Mónica. Opinión pública sobre interrupción voluntaria del embarazo y despenalización del aborto en la Argentina y América Latina. Despenalización, Hoja informativa, n. 8, abril, 2007. Disponible en: www.despenalizacion.org.ar. Consulado 8 de Febrero de 2010.

RAMOS, Silvina; ROMERO, Mónica; BERGALLO, Paola. El acceso al aborto permitido por la ley: un tema pendiente de la política de derechos humanos en Argentina en Derechos Humanos en Argentina. Buenos Aires: Siglo XXI-CELS, 2009, p. 451-491. 
[s/a]. Otro caso testigo para forzar la legislación del aborto. In: NOTIVIDA, año VIII, n. 543, 2008.

SCALA, Jorge. Cultura Contemporánea y Derecho. In: Recrear la cultura de la vida. Córdoba: Encuentro, 2006, p. 13-32.

SHEPPARD, Bonnie. The double discourse on sexual and reproductive rights in Latin America: the chasm between Public policy and private actions y NGO Advocacy Networks in Latin America: lessons from the experience in promoting women's and reproductive rights. In: SHEPPARD, Bonnie. Running the obstacle course to sexual and reproductive health: lessons from Latin America. Santa Barbara: Praeger Publishers, 2006, p. 13-98.

SOLANET, Alberto et al. Abogados católicos contra posible aborto en Mendoza. In: NOTIVIDA, año VIII, n. 542, 2008.

SOLANET, Alberto. El Bicentenario y la pacificación nacional. La Nación, Buenos Aires, 15 abr. 2009. Disponible en: http://www.lanacion.com.ar/nota.asp?nota_ $\mathrm{id}=1118392$.

VAGGIONE, Juan Marco La sexualidad en un mundo post secular. El activismo religioso y los derechos sexuales y reproductivos. In: GERLERO, Mario S. Derecho a la sexualidad. Buenos Aires: Grimberg, 2009.

VATICANO. Mulieris dignitatem. Carta apostólica de Juan Pablo II, 1988. Disponible en: http://www.vatican.va/holy_father/john_paul_ii/apost_letters/documents/hf_jp-ii_apl_15081988_mulieris-dignitatem_sp.html.

VÁZQUEZ, Rodolfo. La cuestión del embrión y algunos problemas de la bioética. In: PÉREZ TAMAYO, Ruy; LISKER, Rubén; TAPIA, Ricardo (Orgs.). La construcción de la bioética. V. I. FCE, México, 2007.

WACQUANT, Löic. Poder simbólico y práctica democrática. In: WACQUANT, Löic (Coord.) El misterio del ministerio. Pierre Bourdieu y la política democrática. Barcelona: Gedisa, 2005, p. 13-22.

ZAMBERLIN, N. El aborto en Argentina. Despenalización, Hoja Informativa n. 3, junio de 2007. Disponible en: www.despenalizacion.org.ar. Consulado 8 de Febrero de 2010.

Recebido: $25 / 03 / 2010$

Aceite final: 22/04/2010 